\title{
Results of the International Comparison of Absolute Gravimeters in Walferdange November 2003
}

Olivier Francis

University of Luxembourg, 6, rue Coudenhove-Kalergi, L-1359 Luxembourg

and European Center for Geodynamics and Seismology, 19, rue Josy Welter, L-7256 Walferdange

Tonie van Dam

European Center for Geodynamics and Seismology, 19 rue Josy Welter, L-7256 Walferdange

M. Amalvict, M. Andrade de Sousa, M. Bilker, R. Billson, G. D'Agostino, S. Desogus, R. Falk, A. Germak, O. Gitlein, D. Jonhson, F. Klopping, J. Kostelecky, B. Luck, J. Mäkinen, D. McLaughlin, E. Nunez, C. Origlia, V. Palinkas, P. Richard, E. Rodriguez, D. Ruess, D. Schmerge, S. Thies, L. Timmen, M. Van Camp, D. van Westrum, H. Wilmes

\begin{abstract}
The results of an international comparison of absolute gravimeters held in Walferdange Luxembourg in November 2003 are presented. The absolute meters agreed with one another with a standard deviation of less than 2 $\mu \mathrm{Gal}\left(1 \mathrm{Gal}=1 \mathrm{~cm} / \mathrm{s}^{2}\right)$ (if we exclude one prototype instrument from the analysis). For the first time, the ability of the operators was put to the test. The comparison indicates that the errors due to the operator are less than $1 \mu \mathrm{Gal}$, i.e. within the observational errors.
\end{abstract}

On November 3rd to November 7th 2003, Luxembourg's European Center for Geodynamics and Seismology (ECGS) hosted an international comparison of absolute gravimeters in the Underground Laboratory for Geodynamics in Walferdange (WULG). This is the first time in the history of geophysics and metrology that 15 absolute gravimeters were brought together in the same location for simultaneous observations. Teams from all over the world including the United States and Brasil, as well as teams from Europe participated, in the comparison (Table 1).

\section{Introduction}

Table 1. Participants in the International Comparison of Absolute Gravimeters.

\begin{tabular}{|c|c|c|c|}
\hline Country & Institution & $\begin{array}{l}\text { Absolute } \\
\text { gravimeter(s) }\end{array}$ & $\begin{array}{l}\text { Relative } \\
\text { gravimeter(s) }\end{array}$ \\
\hline Austria & $\begin{array}{l}\text { Bundesamt für Eich- und Vermessungswesen (BEV), } \\
\text { Vienna }\end{array}$ & JILAg-6 & \\
\hline Belgium & Observatoire Royal de Belgique (ORB), Brussels & FG5-202 & $\begin{array}{l}\text { Scintrex } \\
\text { CG3M-256 }\end{array}$ \\
\hline $\begin{array}{l}\text { Brazil } \\
\text { Finland } \\
\text { France } \\
\quad \text {. }\end{array}$ & $\begin{array}{l}\text { Observatorio Nacional, Rio de Janeiro } \\
\text { Finnish Geodetic Institute, (FGl), Masala } \\
\text { Ecole et Observatoire des Sciences de la Terre (EOST), } \\
\text { Strasbourg }\end{array}$ & $\begin{array}{l}\text { FG5-223 } \\
\text { FG5-221 } \\
\text { FG5-206 }\end{array}$ & \\
\hline Germany & $\begin{array}{l}\text { Bundesamt für Kartographie und Geodäsie (BKG), } \\
\text { Frankfurt }\end{array}$ & FG5-301 & \\
\hline Germany & $\begin{array}{l}\text { Institut für Erdmessung (IfE), Universität Hannover, } \\
\text { Hannover }\end{array}$ & FG5-220 & \\
\hline $\begin{array}{l}\text { ltaly } \\
\text { Luxembourg }\end{array}$ & $\begin{array}{l}\text { Istituto di Metrologia "G. Colonnetti" (IMGC), Turin } \\
\text { European Center for Geodynamics and Seismology, } \\
\text { ECGS }\end{array}$ & $\begin{array}{l}\text { IMGC-02 } \\
\text { FG5-216 }\end{array}$ & $\begin{array}{l}\text { Scintrex-CG5 } \\
021210008\end{array}$ \\
\hline $\begin{array}{l}\text { Czech } \\
\text { Republic } \\
\text { Spain }\end{array}$ & $\begin{array}{l}\text { RIGTC, Geodetic Observatory Pecny } \\
\text { Instituto Geográfico Nacional (IGN), Madrid }\end{array}$ & $\begin{array}{l}\text { FG5-215 } \\
\text { A10-006 }\end{array}$ & \\
\hline $\begin{array}{l}\text { Spain } \\
\text { Switzerland }\end{array}$ & $\begin{array}{l}\text { Instituto Geográfico Nacional (IGN), Madrid } \\
\text { Swiss Federal Office of Metrology and Accreditation } \\
\text { (METAS), Bern-Wabern }\end{array}$ & $\begin{array}{l}\text { FG5-211 } \\
\text { FG5-209 }\end{array}$ & $\begin{array}{l}\text { Scintrex } \\
\text { CG3M-494 }\end{array}$ \\
\hline $\begin{array}{l}\text { UK } \\
\text { USA }\end{array}$ & $\begin{array}{l}\text { Proudman Oceanographic Laboratory (POL), Bidston } \\
\text { United States Geological Survey }\end{array}$ & $\begin{array}{l}\text { FG5-103 } \\
\text { A10-008 }\end{array}$ & \\
\hline
\end{tabular}


In 1999, a laboratory (Figure 1) dedicated to the intercomparison of absolute gravimeters was built within the WULG. The laboratory lies 100 meters below the surface at a distance of $300 \mathrm{~m}$ from the entrance of the mine. To transport the 350 kilograms of equipment (the typical weight of an absolute gravimeter and its peripherals) over the 300 meters to the lab, electric golf carts were used. The cart travels on a smooth newly installed concrete surface.

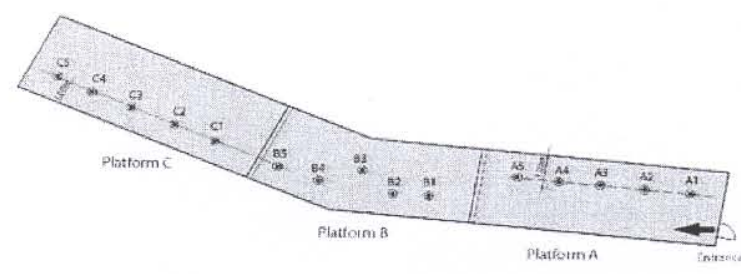

Fig. 1 Underground laboratory where 15 gravimeters can be setup at the same time ( $40 \mathrm{~m}$ length and 3.6 wide)

The WULG is environmentally stable (i.e. constant temperature and humidity within the lab), and is extremely well isolated from anthropogenic noise. It has the power and space requirements to be able to accommodate up 15 instruments operating simultaneously (Figure 2).

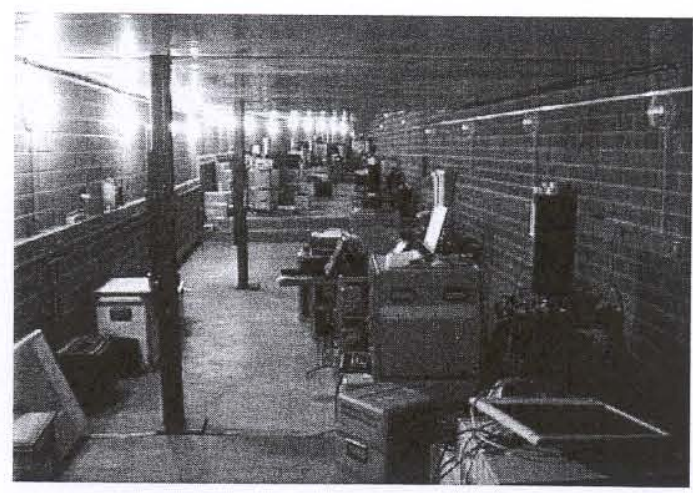

Fig. 2 Picture taken during the comparsion of absolute gravimeters in the Underground Laboratoty for Geodynmaics in Walferdange

Absolute gravimeters are used in geophysics for monitoring gravity variations due to mass changes within the Earth (i.e. the motion of magma underneath volcanoes), mass changes within the Earth's upper layers (i.e. the seasonal variations of continental water storage that might be related to global warming), density changes and vertical displacement caused by deformations of the Earth's crust (i.e. tectonic deformations associated with the build up and release of strain during an earthquake). In metrology, absolute gravimeters are used in the determination of standards derived from the kilogram (ampere, pressure, force). However, because these instruments are 'absolute', to verify that the instruments are operating properly, they must be regularly compared to other instruments of the same accuracy. Being absolute instruments, these gravimeters cannot really be calibrated. Only some of their components (such as the atomic clock or the laser) can be calibrated by comparison with known standards. The only way one currently has to verify their good working order is via a simultaneous intercomparison with other absolute gravimeters of the same and/or if possible even of a different model, to put in evidence systematic errors..

During a comparison, we cannot estimate how accurate the meters are: in fact, as we have no way to know the true value of $g$, we can only investigate the relative offset between instruments. This means that all instruments can suffer from the same unknown and undetectable systematic error. In addition, differences larger than the uncertainty of the measurements, is an indication of possible systematic error.

Intercomparisons of this type are difficult to arrange which is why they have only officially been organized every 4 years by the Bureau International des Poids et Mesures (BIPM) in Sèvres, France. This time scale is not sufficient for most users as most also regularly deploy their instruments for field observations.

For the first intercomparison in Walferdange, 15 meters from 13 countries including 5 types of absolute gravimeters were present: 1 Jilag, 11 FG5s with bulk and fiber interferometer, $2 \mathrm{~A} 10 \mathrm{~s}$, and 1 prototype from IMGC. For the first time, simultaneous observations were taken. In addition an original experiment was conducted to estimate the error due to the operators.

\section{Protocol}

Ideally to compare gravimeters, they should measure at the same site at the same time. Obviously, this is practically impossible. The comparison was spread over three days. The first day, each instrument was installed at one of the 15 sites. The second day, as the WULG is composed of three different platforms, all instruments moved to another site on a different platform and again on the third day. Overall, each instrument occupied at least 3 sites one on each platform. We also planned the observations in such a way, that two different instruments which occupied the same site, did not measure at another common site again. This allows us to compare each instrument to as many other instruments possible. 
Some teams arrived a few days before the comparison and others teams did stay longer afterward. Those extra measurements were also included in the final adjustment.

\section{Data processing}

Raw data of the absolute gravimeters consist of vectors of time intervals between successive positions of the falling object during the drops. To obtain the gravity value, a linear equation representing the equation of motion is fit to the raw data including the vertical gravity gradient which has been measured with relative meters. The procedures followed are the same as at the comparisons in Sèvres (Francis and van Dam, 2003). Geophysical corrections are applied to the raw gravity data: earth tides using observed tidal parameters from the superconducting gravimeter installed in a gallery next to the laboratory, atmospheric pressure using a constant admittance and polar motion effect using pole positions from IERS.

The vertical gravity gradients were measured by three different operators (O. Francis, M. Van Camp and P. Richard) with two Scintrex CG3-M and one Scintrex CG5. Comparisons between the rubidium clocks and the barometers were carried out by $\mathrm{M}$. Van Camp and R. Falk. The results of these comparisons were used in data processing. We did not have any laser calibration as we are not equipped for this.

Most of the data were processed with the "g-soft" version 4.0 from Micro-g Solutions which runs on Microsoft Windows $®$. However, the Jilag gravimeter operating with old electronics is not compatible and the program, "Replay", from "Olivia" was used. This early version of the software contains the same coded algorithms for computing the g-values and the geophysical corrections as in "g-soft". The only difference is in the data input format.

\section{Errors due to the operators}

An original experiment to estimate the operators' error has been performed with the agreement of all the participants. After the third day, all the operators of the FG5s and 1 A-10 left their instruments in the hands of experts from Micro-g Solutions, manufacturer of the FG5. The instruments remained at the same site but were run by Micro-g engineers. The results (Figure 3) show that the measurements agree within the error bar of the observations. There are two exceptions: the FG5\#211 due to a bad collimation of the laser corrected by Micro-g and the FG5\#216 which was operated during the comparison by Micro-g for which we do not have an explanation yet.

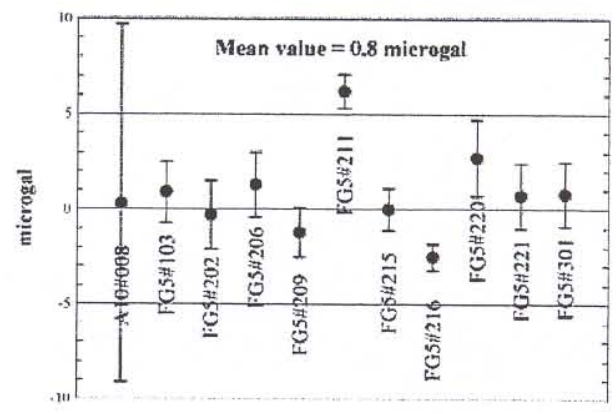

Fig. 3 Difference in the gravity values as measured by the usual operators and the expert operators from Micro-g.

\section{Adjustment of the data}

Data from one instrument (A10\#006) were discarded due to problem with the power supply. Data at site A1 were not included in the final adjustment as only one instrument occupied the site. The data of the prototype gravimeter IMGC-2 were not included in the adjustment because an offset of $-46.7 \mu \mathrm{Gal}$ was detected and would have biased the adjustment. The data from the FG5\#211 were corrected for an offset of $-2.7 \mu \mathrm{Gal} 1$ due to the collimation error (see previous section).

All the gravimeters could not occupy all the sites. To compare their measurements, the following least-square adjustment has been performed:

$$
g_{\mathrm{ik}}=\mathrm{g}_{\mathrm{k}}+\mathrm{e}_{\mathrm{i}}
$$

where $\mathrm{g}_{\text {ik }}$ is the gravity value at the site $\mathrm{k}$ given by the instrument $\mathrm{i}, \mathrm{g}_{\mathrm{k}}$ is the adjusted value at the site $\mathrm{k}$ and $e_{i}$ is the uncertainty containing a systematic component (the offset) and a stochastic component. We assume a systematic error of $2 \mu \mathrm{Gal}$ for the FG5s and Jilag and $5 \mu \mathrm{Gal}$ for the A10 as specified by the manufacturer. For the stochastic component, we took the average value at each site and calculate the difference for each instrument with the average value. Then we computed the standard deviation of this difference, which was used to estimate the precision (the stochastic part) of each instrument.

The results of the adjustment using the complete set of data are displayed in Table 2 and Figures 4. 

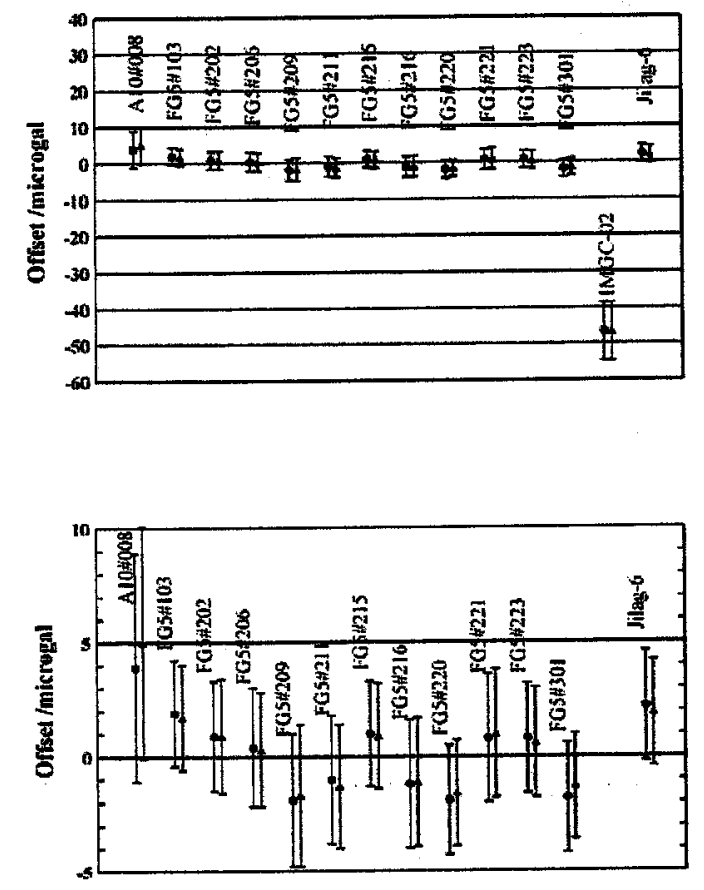

Fig. 4 Relative offsets between the gravimeters for the unweighted (black dots) and weighted (red triangles) adjustments.

The standard deviation of the relative offset between the different instruments varies from 1.8 for the unweighted solution to $1.9 \mu \mathrm{Gal}$ for the weighted solution if we exclude the prototype instrument IMGC-02 which has an offset of -46.7 $\mu \mathrm{Gal}$. It is worth noting that all the error bars cross Table 2. Relative offsets between the gravimeters for the unweighted and weighted adjustments

\begin{tabular}{lccccc} 
Instrument & $\begin{array}{c}\text { Unweighted offset } \\
\text { Average } \\
/ \mu \mathrm{Gal}\end{array}$ & $\begin{array}{c}\text { Error } \\
/ \mu \mathrm{Gal}\end{array}$ & $\begin{array}{c}\text { Weighted offset } \\
\text { Average } \\
/ \mu \mathrm{Gal}\end{array}$ & $\begin{array}{c}\text { Error } \\
/ \mu \mathrm{Gal}\end{array}$ & $\begin{array}{c}\text { Difference } \\
/ \mu \mathrm{Gal}\end{array}$ \\
\hline A10\#008 & 3,9 & 5,0 & 5 & 5,1 & $-1,1$ \\
FG5\#103 & 1,9 & 2,3 & 1,7 & 2,3 & 0,2 \\
FG5\#202 & 0,9 & 2,4 & 0,9 & 2,5 & 0 \\
FG5\#206 & 0,4 & 2,6 & 0,3 & 2,5 & 0,1 \\
FG5\#209 & $-1,9$ & 2,9 & $-1,7$ & 3,1 & $-0,2$ \\
FG5\#211 & -1 & 2,8 & $-1,3$ & 2,7 & 0,3 \\
FGS\#215 & 1 & 2,3 & 0,9 & 2,3 & 0,1 \\
FG5\#216 & $-1,2$ & 2,8 & $-1,1$ & 2,8 & $-0,1$ \\
FG5\#220 & $-1,9$ & 2,4 & $-1,6$ & 2,3 & $-0,3$ \\
FG5\#221 & 0,8 & 2,8 & 1 & 2,8 & $-0,2$ \\
FG5\#223 & 0,8 & 2,4 & 0,6 & 2,4 & 0,2 \\
FG5\#301 & $-1,8$ & 2,4 & $-1,3$ & 2,3 & $-0,5$ \\
IMGC-02 & $-46,7$ & 8,1 & $-46,7$ & 7,9 & 0 \\
Jilag-6 & 2,2 & 2,4 & 1,9 & 2,3 & 0,3 \\
\hline Std & 1,8 & & 1,9 & & \\
Mean & & & & & $-0,09$ \\
\hline
\end{tabular}

